\title{
Reversible Dual-Stimuli-Responsive Chromic Transparent Wood Biocomposites for Smart Window Applications
}

\author{
Archana Samanta,* Hui Chen, Pratick Samanta, Sergei Popov, Ilya Sychugov, and Lars A. Berglund
}

Cite This: ACS Appl. Mater. Interfaces 2021, 13, 3270-3277

Read Online

ABSTRACT: Transparent wood (TW)-based composites are of significant interest for smart window applications. In this research, we demonstrate a facile dual-stimuli-responsive chromic TW where optical properties are reversibly controlled in response to changes in temperature and UV-radiation. For this functionality, bleached wood was impregnated with solvent-free thiol and ene monomers containing chromic components, consisting of a mixture of thermo- and photoresponsive chromophores, and was then UV-polymerized. Independent optical properties of individual chromic components were retained in the compositional mixture. This allowed to enhance the absolute optical transmission to 4 times above the phase change temperature. At the same time, the transmission at $550 \mathrm{~nm}$ could be
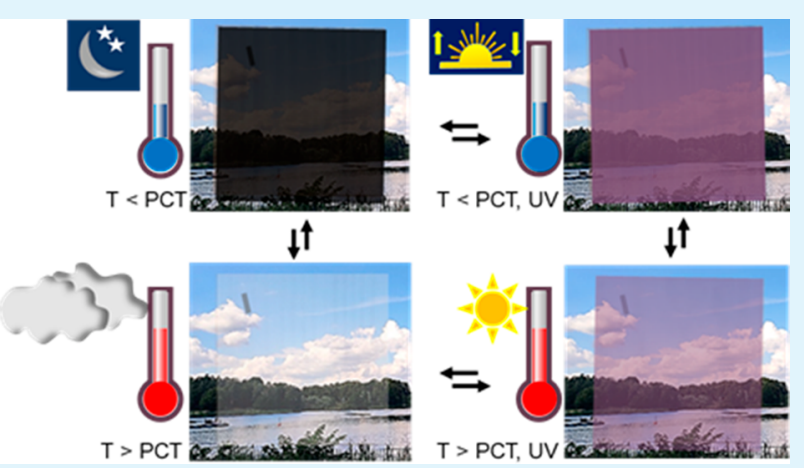
reduced $11-77 \%$, on exposure to UV by changing the concentration of chromic components. Chromic components were localized inside the lumen of the wood structure, and durable reversible optical properties were demonstrated by multiple cycling testing. In addition, the chromic TW composites showed reversible energy absorption capabilities for heat storage applications and demonstrated an enhancement of $64 \%$ in the tensile modulus as compared to a native thiol-ene polymer. This study elucidates the polymerization process and effect of chromic components distribution and composition on the material's performance and perspectives toward the development of smart photoresponsive windows with energy storage capabilities.

KEYWORDS: cellulose composites, dual chromism, temperature responsive, photochromic, heat storage, optical transmittance

\section{INTRODUCTION}

Wood is a renewable natural resource and interesting substrate for implementing in advanced materials due to its hierarchal porous structure from nano- to microscale, high mechanical strength, and the presence of surface functional groups suitable for altering the chemistry or imbibing functional moieties. ${ }^{1-4}$ Transparent wood (TW) has recently emerged as a biocomposite material for applications involving high light transmittance with pliable optical characteristics. 5,6 Wood is made transparent by removing light-absorbing chromophores and filling the voids with a polymer of refractive index close to that of the wood substrate. ${ }^{7-11}$ Although transparent wood was initially developed for the analysis of wood anatomy, ${ }^{12}$ it is now considered as wood-based composite for advanced functional (and simultaneously load-bearing) applications, such as white-light-emitting diodes, ${ }^{13,14}$ solar cells, ${ }^{15,16}$ and luminescent ${ }^{17,18}$ and heat shielding ${ }^{19,20}$ applications in panels and windows. Smart electrodes for electrochromic properties of reversible control of optical properties on application of applied voltage are extending usefulness in various fields, especially for fabricating solar cells. ${ }^{21-28}$ Electrochromic TW was fabricated by coating poly(3,4-ethylenedioxythiophene):poly(styrenesulfonate) (PEDOT:PSS), which can switch to a coloration efficiency of $590 \mathrm{~cm}^{2} \mathrm{C}^{-1}{ }^{29}$ TW with low thermal conductivity, low specific density, enhanced toughness, and shatterproof features can be considered as good candidate for window-like structures instead of brittle glass. ${ }^{30,31}$

One way of advancing existing research on TW for window applications would be to control optical properties in response to environmental (climatic) conditions. The proposition was to develop a temperature- and UV-responsive new type of window model from TW material, which can remain dark and opaque below a certain phase change temperature (PCT), for instance, representing night conditions, thus reducing seethrough properties to maintain privacy. This can be achieved by inclusion of thermochromic (TC) components. At the same time, such a window concept is enabled to sense daylight conditions which can allow the passage of sunlight inside

Received: December 1, 2020

Accepted: December 30, 2020

Published: January 8, 2021 
building by enhancing the light transmission. In addition to the thermochromic effect, under hot weather conditions or midday time, when too much sunlight is undesirable, a smart TW window would respond by changing color to a lighter hue (to allow partial light transmittance) instead of becoming completely dark. The change in color/transmittance is achieved by inclusion of photochromic (PC) components which are receptive to the UV spectral part of sunlight. This investigation, thus, aims at developing of a novel thermo- and photoresponsive TW, which can sense and control color and light transmission at different periods during the day or at different ambient conditions.

There exist previous studies on TW with photochromic additives only, ${ }^{32,25}$ but our goal was to combine thermochromic and photochromic components, lower the haze, and develop a basic understanding of how the fairly complex biocomposite composition influences optical properties of the material. There are also previous studies on thermoresponsive $\mathrm{TW},{ }^{30,33}$ but the present investigation simultaneously targets color change, improved transmittance, reduced haze, and, again, to combine thermo- and photoresponsive performance. As a host polymer, the thiol-ene is used in the present investigation to reduce wood-polymer debond cracks resulting from cure shrinkage and corresponding light scattering. Thiol-enes show gelation late, during polymerization at high degree of reaction, which means that little cure shrinkage occurs in the solid state. Reported volume shrinkage for thiol-ene and PMMA-based polymer systems are $4.1 \%{ }^{34}$ and $20 \%,{ }^{35}$ respectively. In addition, the thiol and ene monomers do not require any organic solvent or prepolymerization of monomers which is used in many reported studies. ${ }^{36} \mathrm{UV}$-curing is a processing advantage of the present thiol-ene, which reduces the energy required to process the biocomposite.

Fundamentals of novel TW biocomposites processing, as well as thermo- and photochromic component composition effects on optical properties, were investigated. The main idea was to gain detailed control of stimuli-responsive optical properties based on exposure to UV-radiation and temperature. Thermo- and photochromic microcapsules were used to avoid potential self- and cross-aggregation and photobleaching degradation of chromophores, which is a known problem for most of the dyes. ${ }^{37,38}$ Hence, establishing the fabrication technology of dual chromic components and understanding their effects on the composite properties will pave a path forward toward novel multifunctional TW composite structures.

\section{EXPERIMENTAL SECTION}

Materials and Chemicals. Balsa wood with density of $170-200$ $\mathrm{kg} \mathrm{m}^{-3}$ was procured from Material $\mathrm{AB}$ (Sweden). Acetone, ethanol absolute (99\%), and sodium hydroxide were supplied from VWR. Hydrogen peroxide (30\%), UV initiator 1-hydroxycyclohexyl phenyl ketone, pentaerythritoltetrakis(3-mercaptopropionate) (PETMP, tetrafunctional thiol monomer), sodium acetate, sodium silicate, and 1,3,5-triallyl-1,3,5-triazine-2,4,6(1H,3H,5H)-trione (TATATO, trifunctional ene monomer) were supplied from Sigma-Aldrich. Acetic acid (Honeywell), diethylenetriaminepentaacetic acid (DTPA, Acros Organics), magnesium sulfate (Scharlau), and sodium chlorite (40\%, Alfa Aesar) were procured and used as received. Thermochromic (TC) and photochromic pigments (PC) in the form of microcapsules were purchased from SFXC dyes (United Kingdom) with average capsule diameters of $5 \pm 2$ and $6 \pm 3 \mu \mathrm{m}$, respectively, as measured from SEM (Figure S1). The thermochromic pigment was based on leuco vat dye with a reversible PCT of $31{ }^{\circ} \mathrm{C}$, where the pigment changed from black to colorless. The photochromic pigment was made from a mixture of potassium nitrate $(50-55 \%)$, silica (18$23 \%)$, sodium nitrate (10-15\%), and azobenzene(butylmethoxydibenzoylmethane) $(7-22 \%)$ and changes from a white to purple hue on exposure to sunlight.

Lignin Modification of Wood (Bleaching Process). The 15 $\times 15 \times 1.1(l \times b \times h) \mathrm{mm}^{3}$ samples were weighed and treated with an aqueous hydrogen peroxide-based bleaching solution at $70{ }^{\circ} \mathrm{C}$. The bleaching solution consisted of sodium silicate $(3.0 \mathrm{wt} \%)$, sodium hydroxide (3.0 wt \%), magnesium sulfate (0.1 wt \%), DTPA (0.1 wt $\%)$, and hydrogen peroxide (4.0 wt \%) in deionized (DI) water as per the process reported elsewhere. ${ }^{39}$ Samples were treated until they turned visibly white.

Fabrication of Transparent Wood. Bleached wood samples were washed with deionized water and were solvent exchanged with ethanol and acetone. These wood templates were then infiltrated with stoichiometric mixtures of thiol and allyl functionalized monomers of PETMP and TATATO containing the UV-initiator 1-hydroxycyclohexyl phenyl ketone (0.5 wt \%) along with measured quantities of thermochromic or/and photochromic components as detailed in Table 1 under vacuum for $24 \mathrm{~h}$. The acetone present in the samples

Table 1. Formulation Details and Sample Codes for Various TW Composites

$\begin{array}{lccc}\text { sample code } & \begin{array}{c}\text { chromic }^{\text {content }}{ }^{a} \\ (\text { wt } \%)\end{array} & \begin{array}{c}\text { thermochromic } \\ \text { component (TC) } \\ (\%)\end{array} & \begin{array}{c}\text { photochromic } \\ \text { component (PC) } \\ (\%)\end{array} \\ \begin{array}{l}\text { Thiol-ene } \\ \text { TW }\end{array} & 0 & 0 & 0 \\ \text { T1000.1 } & 0.1 & 100 & 0 \\ \text { T1000.5 } & 0.5 & 100 & 0 \\ \text { T1001 } & 1 & 100 & 0 \\ \text { T1003 } & 3 & 100 & 0 \\ \text { T1005 } & 5 & 100 & 0 \\ \text { T30P700.1 } & 0.1 & 30 & 70 \\ \text { T30P700.5 } & 0.5 & 30 & 70 \\ \text { T30P701 } & 1 & 30 & 70 \\ \text { T30P703 } & 3 & 30 & 70 \\ \text { T30P705 } & 5 & 30 & 70 \\ \text { T50P500.1 } & 0.1 & 50 & 50 \\ \text { T50P500.5 } & 0.5 & 50 & 50 \\ \text { T50P501 } & 1 & 50 & 50 \\ \text { T50P503 } & 3 & 50 & 50 \\ \text { T50P505 } & 5 & 50 & 50 \\ \text { T70P300.1 } & 0.1 & 70 & 30 \\ \text { T70P300.5 } & 0.5 & 70 & 30 \\ \text { T70P301 } & 1 & 70 & 30 \\ \text { T70P303 } & 3 & 70 & 30 \\ \text { T70P305 } & 5 & 70 & 30 \\ \text { P1000.1 } & 0.1 & 0 & 100 \\ \text { P1000.5 } & 0.5 & 0 & 100 \\ \text { P1001 } & 1 & 0 & 100 \\ \text { P1003 } & 3 & 0 & 100 \\ \text { P1005 } & 5 & 0 & \end{array}$

${ }^{a}$ Weight percent on the basis of monomer content.

evaporated during the vacuum infiltration process. Samples were additionally kept at $50{ }^{\circ} \mathrm{C}$ for $30 \mathrm{~min}$ to remove residual acetone, monitored by weight loss assessment. Monomer infiltrated samples were then sandwiched between two glass slides and cured for $4 \mathrm{~min}$ by illumination from four $9 \mathrm{~W} 365 \mathrm{~nm}$ UV-lamps: two on opposite sides of and two above the sample to ensure uniform curing. The mass fractions of wood and polymer in the resultant composites were determined from the density difference between bleached and the 


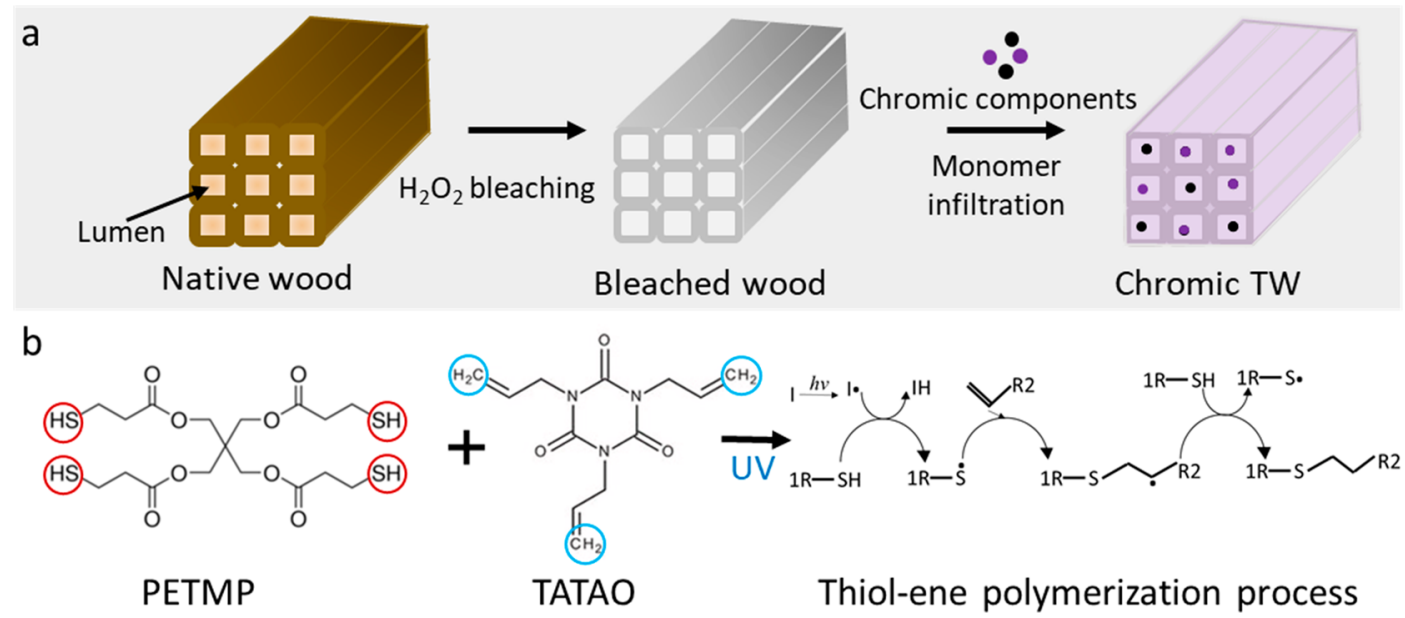

Figure 1. (a) Fabrication steps for chromic TW. (b) Schematic sketch for representation of the polymerization process.
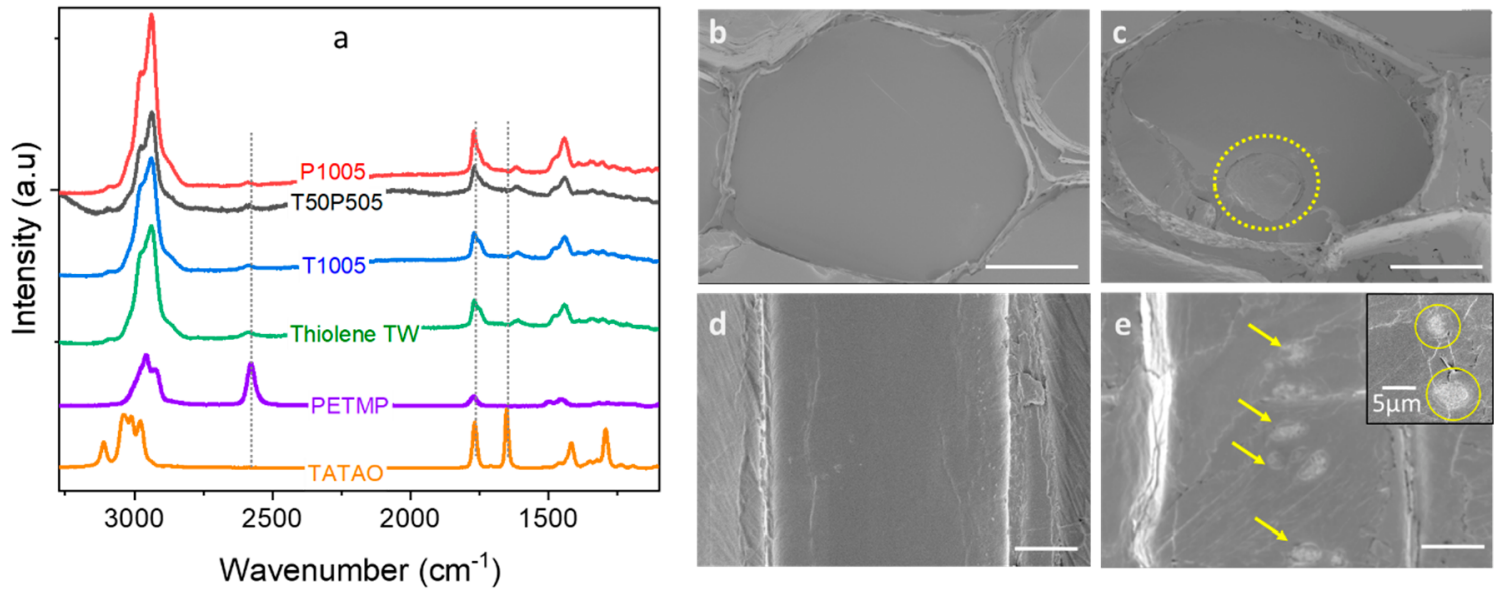

Figure 2. (a) Raman analysis of thiol-ene monomers and chromic TW composites. The gray lines correspond to thiol stretching $\left(2575 \mathrm{~cm}^{-1}\right)$, ketone stretching $\left(1765 \mathrm{~cm}^{-1}\right)$, and allyl bending $\left(1650 \mathrm{~cm}^{-1}\right)$. SEM of cross sections of (b) thiol-ene TW and (c) T50P505. Longitudinal sections of (d) thiol-ene TW and (e) T50P505. The spheres and arrows indicate the presence of chromic components in the system. The inset in (e) indicates an enlarged image of the chromic components. White bars in the pictures indicate a scale of $10 \mu \mathrm{m}$, unless otherwise specified.

cured TW samples after drying the bleached samples at $105 \pm 3{ }^{\circ} \mathrm{C}$ for $24 \mathrm{~h}$.

Characterization. The morphology of the TW composites and the interfacial polymer-wood bonding was analyzed by using fieldemission scanning electron microscopy (FE-SEM, Hitachi S-4800) operating at accelerating voltage of $1.0 \mathrm{kV}$ and a working distance of $9.8 \mathrm{~mm}$. Samples were cryo-fractured in liquid nitrogen before analyzing their cross sections.

Differential scanning microscopy was conducted on a TA 2920 modulated DSC. Samples were ramped from -50 to $100{ }^{\circ} \mathrm{C}$, cooled to $-50{ }^{\circ} \mathrm{C}$, and again reheated to $100{ }^{\circ} \mathrm{C}$ at $10^{\circ} \mathrm{C} \mathrm{min}^{-1}$ under a nitrogen environment. The enthalpy of melting from the second heating cycle was analyzed for comparison of thermal energy absorption during the transition from the black to colorless state.

Raman spectra were measured on the freeze-fractured cross sections from TW samples by using confocal Raman microscopy (Jobin Yvon HR800 UV, Horiba) together with a light source from a $514 \mathrm{~nm}$ laser (Stellar-Pro, Modu-laser) and a mechanized stage. Spectra were averaged from 10 scans and analyzed for comparison.

Tensile tests were performed by using an Instron 5944 (USA) instrument equipped with a $500 \mathrm{~N}$ load cell, with sample dimensions of $50 \times 5 \times 1 \mathrm{~mm}^{3}$. The tests were performed with a $10 \% \mathrm{~min}^{-1}$ strain rate and gauge length of $25 \mathrm{~mm}$. Samples were preconditioned for 24 $\mathrm{h}$ and tested in a room at a temperature of $22 \pm 1{ }^{\circ} \mathrm{C}$ with $50 \pm 2 \%$ relative humidity.
Optical measurements were performed by using an integrating sphere in the visible and NIR wavelength region (400-1000 nm) according to ASTM D1003 "Standard Method for Haze and Luminous Transmittance of Transparent Plastics" ${ }^{40}$ by using a quartz tungsten halogen light source (model 66181 from Oriel Instruments) as reported earlier. ${ }^{41}$ The sample was placed in front of an input port of the integrating sphere, illuminated with quartz tungsten halogen light source. The output light was collected through an optical fiber connected to an integrating sphere. Each sample was measured three times, and the results were statistically averaged. Samples were exposed to a hot air gun aimed to heat the sample uniformly from all sides and were equilibrated by heating for $1 \mathrm{~min}$ to achieve a surface temperature of $35 \pm 2{ }^{\circ} \mathrm{C}$. Above the PCT, the transmission curve stabilized, and no further changes were observed by increasing the temperature further. For transmission and haze measurement under UV, samples were illuminated with a UV torch operating at $360 \mathrm{~nm}$ with $3 \mathrm{~mW}$ power. Samples showed a response time of $4 \pm 1 \mathrm{~s}$ for changing to purple on exposure to UV (when illuminated with a UV torch at $360 \mathrm{~nm}$ with $3 \mathrm{~mW}$ power) and a response time of $6 \pm 1 \mathrm{~s}$ to return to their native hue after removal from the UV exposure.

\section{RESULTS AND DISCUSSION}

Fabrication and Characterization of TW Composites. Chromic transparent wood composites (TW) were made by using a two-step process as shown in Figure 1a. In the first 
a
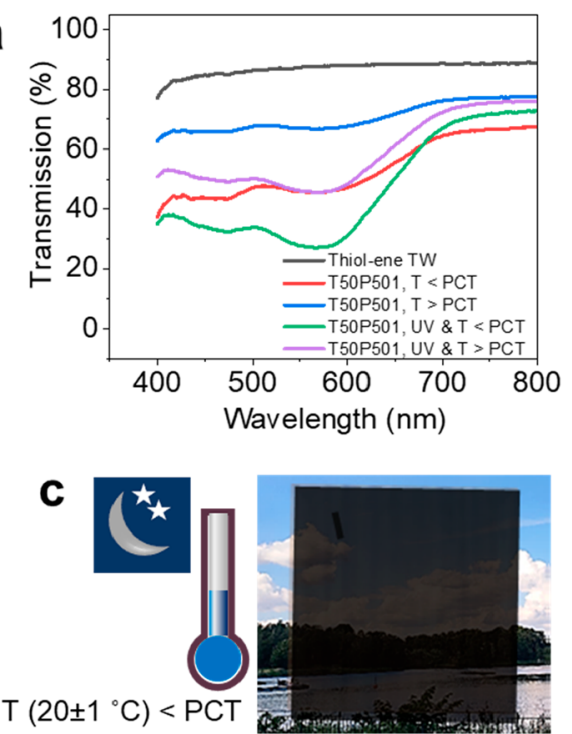

(i)

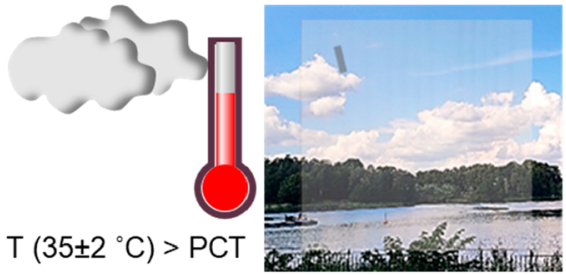

(iii)
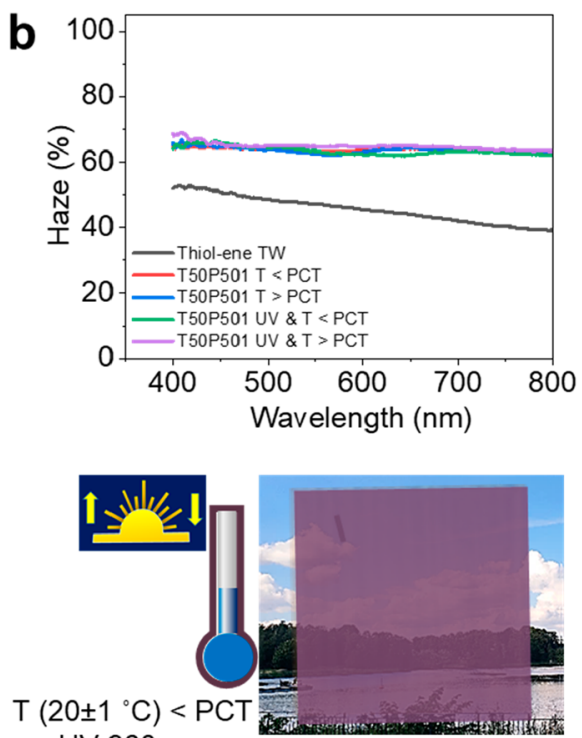

(ii)

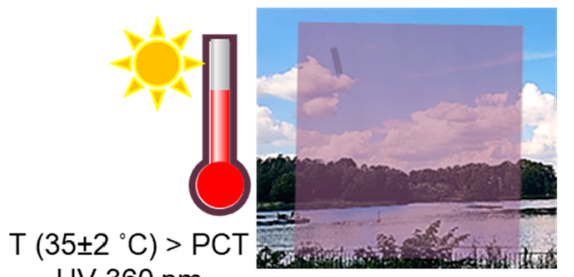

(iv)

Figure 3. (a) Transmission and (b) haze graphs of a representative sample T50P501 on exposure to various conditions of temperature and/or UV mimicking external climatic conditions. (c) Images demonstrating visual change in transmission and color: (i) below PCT, $20 \pm 1{ }^{\circ} \mathrm{C}$; (ii) UV exposure at $360 \mathrm{~nm}$, below PCT of $20 \pm 1{ }^{\circ} \mathrm{C}$; (iii) above PCT, $35 \pm 2{ }^{\circ} \mathrm{C}$; and (iv) UV exposure at $360 \mathrm{~nm}$, above PCT of $35 \pm 2{ }^{\circ} \mathrm{C}$.

step, hydrogen peroxide bleaching was performed to remove the lignin chromophore groups. In the second step, the bleached wood sample was impregnated with a mixture of thermo- and photochromic components as well as thiol and ene monomers along with UV initiator. The sample was then polymerized under UV-light, and free radical polymerization mechanism between thiol and ene monomers is shown in Figure $1 \mathrm{~b}$. Note that the resulting polymer matrix impregnated in the bleached wood substrate was a chemically cross-linked thermoset. The resulting mass of polymer in the thiol-ene TW composites was $89 \pm 2 \%$.

Raman analysis of the chromic TW composites was carried to quantify the degree of cure in the presence of chromic components. The characteristic monomer peaks were identified and compared to the control TW composite containing no externally added chromic components (Figure 2a). The ene monomer (TATAO) was characterized by allyl stretching (3095 $\left.\mathrm{cm}^{-1}\right)$ and allyl bending $\left(1650 \mathrm{~cm}^{-1}\right)$, and the thiol monomer was characterized by ketone stretching at (1765 $\mathrm{cm}^{-1}$ ). The weak peak at $1600 \mathrm{~cm}^{-1}$, corresponding to ring deformation mode, reveals some retainment of lignin in the bleached wood substrate. The degree of polymerization for the thiol and ene monomers was obtained by comparing integrals of peaks corresponding to thiol stretching $\left(2575 \mathrm{~cm}^{-1}\right)$ and allyl bending $\left(1650 \mathrm{~cm}^{-1}\right)$ normalized against ketone stretching $\left(1765 \mathrm{~cm}^{-1}\right)$ and was calculated to be $94 \pm 3 \%$ and $99 \pm 1 \%$, respectively, in the lumen of the thiol-ene TW without any chromic component. The range of these values remained unaltered in the presence of chromic components.
Absence of significant shift in characteristic peak position or variation in peak intensity in the chromic TW as compared to the control thiol-ene TW indicated that the presence of chromic components do not affect the polymerization process. Cryo-fractured cross sections and longitudinal sections of the samples were observed under SEM, shown in Figure $2 b-d$. As can be observed, polymer infiltration was successful in the lumen (empty center of wood cell) of the bleached balsa. The presence of TC and PC components was observed inside the lumen of a representative sample T50P501, as shown in Figures $2 c$ and $2 \mathrm{e}$, respectively. While the $\mathrm{PC}$ component stands out in contrast in the SEM image, the TC needs careful observation as it has low contrast difference compared to the polymer matrix. The dimensions of the components are in correspondence to the original structures (Figure S1). We conclude here that chromic components were successfully infiltrated along with the monomers and were located in the lumen space of the wood template without observable debond gaps between wood and polymer matrix. There was no aggregation of chromic components because microcapsules were spatially surrounded by the polymer matrix system.

Optical Properties and Materials Design. TW from the thiol-ene monomer sample ( $1.1 \mathrm{~mm}$ thick) without any chromic components showed a transmission of $87 \pm 2 \%$ and haze of $47 \pm 2 \%$ at $550 \mathrm{~nm}$, as shown in Figure 3a,b. TW containing 1 wt \% of black reversible TC (T1001), with respect to the polymer content, was analyzed for transmission below and above the PCT. The transmission value of T1001 at $550 \mathrm{~nm}$ increased by $146 \%$ (from $26 \pm 1 \%$ to $64 \pm 2 \%$, 

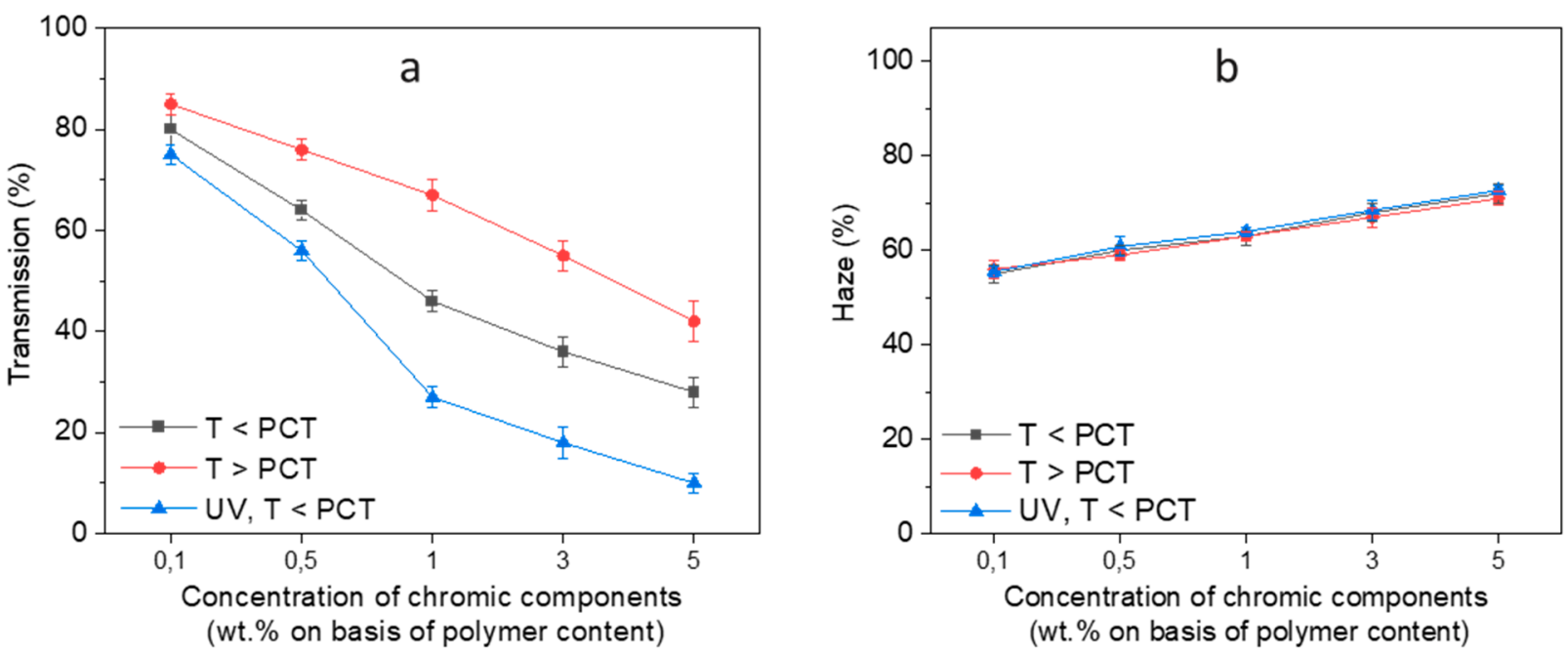

Figure 4. (a) Transmission and (b) haze values at $550 \mathrm{~nm}$ of T50P50 TW composites containing equal proportions of TC and PC components with varying concentration of chromic components above and below PCT and on exposure to UV, respectively.

absolute transmission) above the PCT of $31{ }^{\circ} \mathrm{C}$ (Figure S2a,b). Samples showed a transition time of $1-2 \mathrm{~s}$ to return from colorless to native black state when the surface temperature dropped below the PCT. Transmission values at $550 \mathrm{~nm}$ of TW samples with lowest (0.01 wt \%, T1000.1) and highest (5 wt \%, T1005) content of TC increased by $13 \%$ (from $76 \pm 2$ to $86 \pm 1 \%$, absolute transmission) and $300 \%$ (from $10 \pm 2 \%$ to $40 \pm 3 \%$, absolute transmission), respectively, above the PCT. Variation in the enhancement of transmission above PCT is found to be proportional to the TC content. This can allow flexible design of TW with desired thermoresponsive optical properties, by judiciously altering the TC concentration. The realized here lack of TC agglomeration is central for such a linear performance.

On exposure to UV (illuminated with a UV torch operating at $360 \mathrm{~nm}$ with $3 \mathrm{~mW}$ power), the transmission at $550 \mathrm{~nm}$ was reduced by $58 \%$ (from $66 \pm 4 \%$ to $28 \pm 3 \%$, absolute transmittance) in samples with 1 wt \% PC (P1001) with respect to the pristine polymer phase, as shown in Figure S2q,s. Samples showed a response time of $4 \pm 1 \mathrm{~s}$ for changing to purple on exposure to UV and a response time of $6 \pm 1 \mathrm{~s}$ to return to their native hue after removal from UV exposure. The reduction in transmission at $550 \mathrm{~nm}$ on exposure to UV can be varied from $11 \%$ (from $84 \pm 2 \%$ to $74 \pm 2 \%$, absolute transmittance) to $77 \%$ (from $44 \pm 2 \%$ to $10 \pm 3 \%$, absolute transmittance) by changing the $\mathrm{PC}$ in the samples from $0.1 \mathrm{wt}$ $\%(\mathrm{P} 1000.1)$ to 5 (P1005) wt \%, respectively, on the basis of the polymer content, as represented in Table S1. Thus, similarly to TC performance, TW can be designed to specific UV-responsive optical properties by simply altering the PC content.

For the final goal of this study TC and PC counterparts were combined to fabricate dual-stimuli-responsive TW composites. The transmission of a representative sample T50P501 (containing equal mass ratios of TC and PC) below and above PCT and UV exposure below and above PCT are shown in Figure $3 \mathrm{a}$ and Table S1. The transmission at $550 \mathrm{~nm}$ increased to $48 \%$ (from $46 \pm 1 \%$ to $68 \pm 3 \%$, absolute transmission) above PCT and under UV exposure reduced to $41 \%$ (from $46 \pm 1 \%$ to $27 \pm 2 \%$, absolute transmittance) below the phase change point in this composition. T50P501 visibly illustrates noticeable color change effects at varying conditions of temperature and UV (Figure 3c), a demonstration to mimic external environment conditions. The material clearly demonstrates its potential for fabricating dual-stimuli-responsive smart windows.

To study the influence of compositional effect (TC and PC) on optical properties of resultant TW, the ratio of TC/PC was varied as $30 / 70,50 / 50$, and $70 / 30$ percentage proportion, with a constant of 1 wt \% concentration of chromic component. Transmission values at $550 \mathrm{~nm}$ are shown in Figure 4a, Figure S2e $-p$, and Table S1. The higher the TC content, the higher is the influence on transmission percent above PCT. Similarly, the higher the content of PC, the greater is the absorption of UV spectral part. To validate this impact in more details, the concentration of the chromic component was then increased from 0.1 to $5 \mathrm{wt} \%$ with respect to polymer content. It is evident from the transmission data that higher chromic component content provides stronger response on the optical properties on exposure to temperature or UV. The resultant TW properties are governed by the chromic component content and component properties. These properties are retained in the well-dispersed compositional mixture and unaffected by the process of polymerization. The optical response can thus be controlled by varying the ratio and content of individual chromic components in a wide range of concentrations.

Haze is an important characteristic of a potential material for building envelopes. It is defined as a fraction of transmitted light deviating more than $1.5^{\circ}$ from the ballistic photon direction, that is, scattered light carrying no information. The haze of the TW composites was measured individually below and above PCT in the absence or presence of UV illumination, as shown in Figure $4 \mathrm{~b}$ and Table S1. Haze values at lowest chromic component concentration ( 0.1 wt \%) containing either TC or PC were close to the haze of thiol-ene TW, $47 \pm$ $2 \%$ at $550 \mathrm{~nm}$. The haze values slightly increased with higher chromic component content, and the trend was the same for samples containing either TC, PC, or both. Microscopically, haze depends on the refractive index mismatch between polymer and wood substrate and on scattering defects such as voids or interfacial gaps between the polymer and the wood tissue in the system. ${ }^{42}$ For a given system, the refractive index for the polymer $(1.56)$ and wood $(\mathrm{RI}=1.53,1.53$, and 1.61 for 
cellulose, hemicellulose, and lignin, respectively) is fixed, whereas the number of scattering interfaces increases by increasing the content of chromic component. ${ }^{43}$ Therefore, the haze values slightly increase with increased content of microcapsules in the system. As the number of scattering interfaces remain the same, no noticeable change in the haze values was observed for a given sample at different experimental conditions of temperature and UV or a combination of both.

Previous studies on photochromic TW have reported very high haze values of $95 \%(0.2 \mathrm{~mm} \text { thick basswood })^{32}$ and $99 \%$ ( $2 \mathrm{~mm}$ balsa, density not specified) with inclusion of 0.05 and $1.5 \mathrm{wt} \%$ of photochromic component, respectively. ${ }^{44}$ Because wood density and polymer content are not reported, it is difficult to compare the haze values with our studies. A 47$53 \%$ lower haze $(65 \pm 2 \%$ at $550 \mathrm{~nm}, 1.1 \mathrm{~mm}$ balsa with density $170-200 \mathrm{~kg} \mathrm{~m}^{-3}$ ) was achieved in P1003 with more than twice the content of PC (3wt \%) compared to previous reports. This is possibly due to lower cure shrinkage and less interface debond gaps in wood-thiol-ene compared to wood-PMMA composites. ${ }^{43}$ A higher content of chromic components not only increases the optical effects of transmission and absorbance but also increases the haze values in the composite. The trade-off between enhanced chromic properties and haze should be estimated depending on particular applications. In this study, T50P501 containing two chromic components showed adequate stimuli-responsive change in chromic properties, but with significantly lower haze values at higher content of chromic components compared to previous work. $^{32}$

Durability Studies. Sample T50P50 containing both TC and PC was submerged in water and was placed in oven at 40 ${ }^{\circ} \mathrm{C}$ for 14 days and then exposed to four $9 \mathrm{~W} 365 \mathrm{~nm} \mathrm{UV}$ lamps for $6 \mathrm{~h}$. No noticeable change $(<1 \%)$ was observed (not shown) in the transmission values above PCT or on exposure to UV compared to the native control samples. The haze was $63 \pm 2 \%$ in T50P501, and there was no observable change in haze values before and after exposure, indicating that the scattering interfaces are not changed. This substudy indicates that the TC and PC components demonstrate durable optical properties and are resistant to leaching as they are located inside the lumen of the wood surrounded by the thiol-ene polymer matrix.

Reversible Energy Absorption Capabilities of Chromic TW Composites. The presence of the TC component leads to energy absorption, which is an important characteristic in thermal energy storage applications for smart windows. The thermal storage cycles involve absorption and release of energy at $31{ }^{\circ} \mathrm{C}$, the PCT for the TC component. The heating and cooling cycles of the TW composites with varying TC components and their enthalpy of fusion are presented in Figure S3. Native balsa and thiol-ene TW composite without any chromic component obviously do not show any enthalpy of fusion. TC composites show a fusion temperature at $31^{\circ} \mathrm{C}$ and an enthalpy of fusion of $124 \mathrm{~J} \mathrm{~g}^{-1}$.

A peak melting temperature of $31{ }^{\circ} \mathrm{C}$, the characteristic phase reversal temperature of the TC component, was observed in all the samples. The enthalpy of melting was directly proportional to the TC content in the system as shown in Figure 5. The reliability of the absorption enthalpy was determined by repeating 20 heat - cool cycles from 0 to $50{ }^{\circ} \mathrm{C}$ for representative sample T50P501 (containing equal mass ratios of TC and PC components). The peak melting

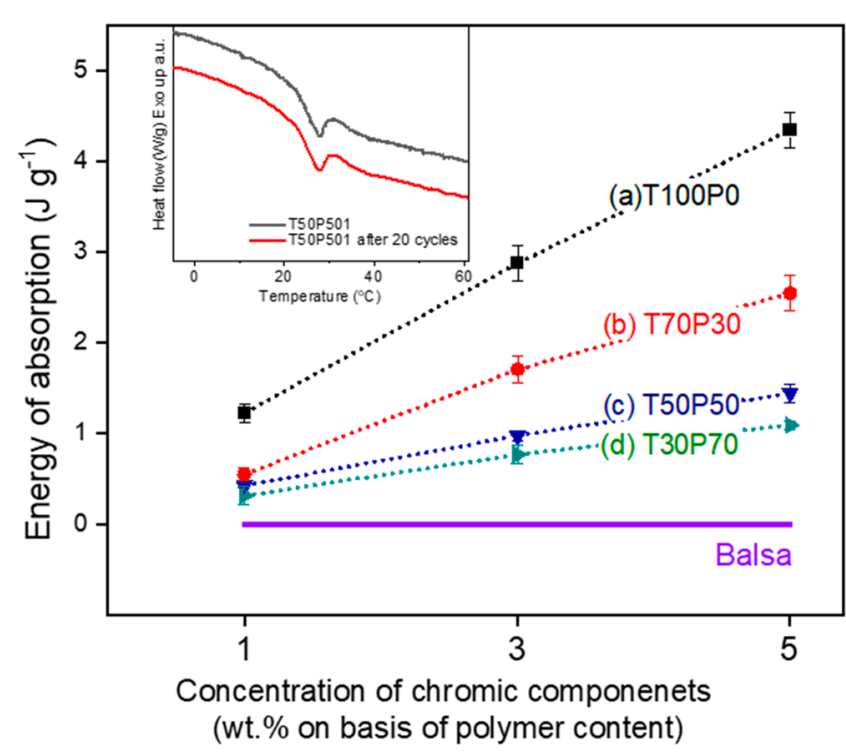

Figure 5. Energy absorption analysis of TW composites. TW with (a) $100 \%$ TC, (b) $70 \%$ TC and $30 \%$ PC, (c) $50 \%$ TC and $50 \%$ PC, and (d) $30 \% \mathrm{TC}$ and $70 \% \mathrm{PC}$ at concentrations of 1,3 , and 5 wt $\%$ on the basis of polymer content. Inset at the top left corner demonstrates negligible change in enthalpy of absorption of a representative sample T50P501 after 20 heat-cool cycles from 0 to $50{ }^{\circ} \mathrm{C}$.

temperature and the enthalpy of melting were observed to be at $31{ }^{\circ} \mathrm{C}$ and $0.422 \pm 0.3 \mathrm{~J} \mathrm{~g}^{-1}$, respectively, after 20 cycles showing no apparent change in energy absorption compared to the control sample. TW composites therefore can be suitable for durable reversible storage applications. Successful processing is important, so that thermochromic moieties become welldispersed in the final material and with few optical defects.

Mechanical Properties of Chromic TW Composites. Mechanical tensile properties were measured in the fiber direction to investigate the influence, if any, of TC and PC components. Stress-strain curves are shown in Figure S4, and the values are presented in Table 2. Native $1.1 \mathrm{~mm}$ thiol-ene

Table 2. Mechanical Properties of Chromic TW Composites

\begin{tabular}{lccc}
\multicolumn{1}{c}{ sample } & $\begin{array}{c}\text { tensile strength } \\
(\mathrm{MPa})\end{array}$ & $\begin{array}{c}\text { modulus } \\
(\mathrm{GPa})\end{array}$ & $\begin{array}{c}\text { strain at break } \\
(\%)\end{array}$ \\
Thiol-ene film & $46 \pm 3$ & $2.2 \pm 0.4$ & $14 \pm 3$ \\
Thiol-ene TW & $61 \pm 2$ & $3.6 \pm 0.3$ & $1.8 \pm 0.3$ \\
T50P501 & $59 \pm 2$ & $3.6 \pm 0.4$ & $1,9 \pm 0.2$ \\
T1001 & $60 \pm 2$ & $3.7 \pm 0.3$ & $1.9 \pm 0.4$ \\
P1001 & $61 \pm 3$ & $3.8 \pm 0.5$ & $1.8 \pm 0.2$ \\
\hline
\end{tabular}

samples demonstrated tensile strength and modulus of $46 \pm 2$ $\mathrm{MPa}$ and $2.2 \pm 0.3 \mathrm{GPa}$, respectively. For thiol-ene TW, a relative enhancement by $33 \%$ and $64 \%$ in the tensile strength and modulus values, respectively, was obtained as compared to the native thiol-ene material. Thus, efficient reinforcement of the thiol-ene was achieved with $11 \pm 2 \mathrm{wt} \%$ wood in the composite system. A representative TW composite containing $\mathrm{TC}$ and PC and a combination of TC and PC in equal mass ratios, i.e., T1001, P1001, and T50P501, respectively, were analyzed, and their average tensile strength and modulus values are given in Table 2. As can be observed, tensile properties are not affected by inclusion of chromic components. The chromic components are located inside the lumen of the wood structure, completely embedded in the thiol-ene polymer 
matrix, and ultimate failure is likely to be controlled by the wood substrate rather than by the polymer matrix.

\section{CONCLUSIONS}

Reversible chromic transparent wood, which is optically responsive to external stimuli of temperature or UV-light, was fabricated by using photopolymerization in a solvent-free process. Individual TC and PC properties are retained in the system as the components were selected to be nonreactive to each other as well as with the polymer system as a whole. The chromic components were found to be located inside the lumen of the wood structure, emphasizing their long-term retain compared to conventional chromic surface coating processes. Increase in the chromic component inclusion into the TW not only enhances the chromic optical effect but also slightly increases the haze of the composite. The selected trade-off between the enhancement of chromic properties and haze can depend on particular applications and can be realized by controlling the microcapsule load. The presence of TC also resulted in reversible energy absorption capacity, showing potential of these TW composites for thermal energy storage. Mechanical properties of the chromic TW composites are much improved compared with the neat polymer and on par with that of the native thiol-ene TW. Smart chromic TW structures can therefore be manufactured without compromising the mechanical properties of the native composite. This study explores the possibility toward the development of smart windows with energy storage capabilities and also demonstrates reversible dual-stimuli optical response from the woodbased biocomposites.

\section{ASSOCIATED CONTENT}

\section{SI Supporting Information}

The Supporting Information is available free of charge at https://pubs.acs.org/doi/10.1021/acsami.0c21369.

SEM images of TC and PC pigments; transmission plots of chromic TW composites containing various compositions of chromic contents on exposure to temperature, UV, or both; table showing transmission values of chromic TW at $550 \mathrm{~nm}$ on exposure to UV, temperature, or both; DSC plots of TW composites; mechanical properties of TW composites (PDF)

\section{AUTHOR INFORMATION}

\section{Corresponding Author}

Archana Samanta - Department of Applied Physics, KTH Royal Institute of Technology, Stockholm 114 19, Sweden; (1) orcid.org/0000-0003-3595-5264; Email: archanas@ kth.se

\section{Authors}

Hui Chen - Department of Fibre and Polymer Technology, Wallenberg Wood Science Center, KTH Royal Institute of Technology, Stockholm 100 44, Sweden; (C) orcid.org/00000001-8181-8493

Pratick Samanta - Department of Fibre and Polymer Technology, Wallenberg Wood Science Center, KTH Royal Institute of Technology, Stockholm 100 44, Sweden

Sergei Popov - Department of Applied Physics, KTH Royal Institute of Technology, Stockholm 114 19, Sweden; (1) orcid.org/0000-0002-3627-8085
Ilya Sychugov - Department of Applied Physics, KTH Royal Institute of Technology, Stockholm 114 19, Sweden; (1) orcid.org/0000-0003-2562-0540

Lars A. Berglund - Department of Applied Physics and Department of Fibre and Polymer Technology, Wallenberg Wood Science Center, KTH Royal Institute of Technology, Stockholm 114 19, Sweden; (1) orcid.org/0000-0001-58182378

Complete contact information is available at: https://pubs.acs.org/10.1021/acsami.0c21369

\section{Funding}

This project has received funding from the European Research Council (ERC) under the European Union's Horizon 2020 research and innovation program (grant agreement no. 742733, Wood NanoTech) and from the Knut and Alice Wallenberg Foundation through the Wallenberg Wood Science Center.

\section{Notes}

The authors declare no competing financial interest.

\section{ACKNOWLEDGMENTS}

Martin Höglund is acknowledged for constructive discussions related to transparent wood fabrication. Erik Jungstedt is acknowledged for assistance in mechanical property measurements.

\section{ABBREVIATIONS}

TW, transparent wood; CC, chromic components; PETMP, pentaerythritoltetrakis(3-mercaptopropionate); TATAO, 1,3,5-triallyl-1,3,5-triazine-2,4,6(1H,3H,5H)-trione; DSC, differential scanning calorimetry; TC, thermochromic component; PC, photochromic component; PCT, phase change temperature.

\section{REFERENCES}

(1) Zhu, H.; Luo, W.; Ciesielski, P. N.; Fang, Z.; Zhu, J. Y.; Henriksson, G.; Himmel, M. E.; Hu, L. Wood-Derived Materials for Green Electronics, Biological Devices, and Energy Applications. Chem. Rev. 2016, 116 (16), 9305-9374.

(2) Frey, M.; Schneider, L.; Masania, K.; Keplinger, T.; Burgert, I. Delignified Wood-Polymer Interpenetrating Composites Exceeding the Rule of Mixtures. ACS Appl. Mater. Interfaces 2019, 11 (38), 35305-35311.

(3) Ates, B.; Koytepe, S.; Ulu, A.; Gurses, C.; Thakur, V. K. Chemistry, Structures, and Advanced Applications of Nanocomposites from Biorenewable Resources. Chem. Rev. 2020, 120 (17), 9304-9362.

(4) Gurunathan, T.; Mohanty, S.; Nayak, S. K. A Review of the Recent Developments in Biocomposites Based on Natural Fibres and Their Application Perspectives. Composites, Part A 2015, 77, 1-25.

(5) Li, Y.; Vasileva, E.; Sychugov, I.; Popov, S.; Berglund, L. Optically Transparent Wood: Recent Progress, Opportunities, and Challenges. Adv. Opt. Mater. 2018, 6 (14), 1800059.

(6) Li, Y.; Fu, Q.; Yu, S.; Yan, M.; Berglund, L. Optically Transparent Wood from a Nanoporous Cellulosic Template: Combining Functional and Structural Performance. Biomacromolecules 2016, 17 (4), 1358-1364.

(7) Ansell, M. P. Wood Microstructure - A Cellular Composite. In Wood Composites; Elsevier: 2015; pp 3-26.

(8) Chen, C.; Kuang, Y.; Zhu, S.; Burgert, I.; Keplinger, T.; Gong, A.; Li, T.; Berglund, L.; Eichhorn, S. J.; Hu, L. Structure-PropertyFunction Relationships of Natural and Engineered Wood. Nat. Rev. Mater. 2020, 5 (9), 642-666. 
(9) Ajao, O.; Jeaidi, J.; Benali, M.; Restrepo, A.; El Mehdi, N.; Boumghar, Y. Quantification and Variability Analysis of Lignin Optical Properties for Colour-Dependent Industrial Applications. Molecules 2018, 23 (2), 377.

(10) Horikawa, Y.; Tsushima, R.; Noguchi, K.; Nakaba, S.; Funada, R. Development of Colorless Wood via Two-Step Delignification Involving Alcoholysis and Bleaching with Maintaining Natural Hierarchical Structure. J. Wood Sci. 2020, 66 (1), 37.

(11) Wu, Y.; Wu, J.; Yang, F.; Tang, C.; Huang, Q. Effect of $\mathrm{H}_{2} \mathrm{O} 2$ Bleaching Treatment on the Properties of Finished Transparent Wood. Polymers 2019, 11 (5), 776.

(12) Fink, S. Transparent Wood - A New Approach in the Functional Study of Wood Structure. Holzforschung 1992, 46 (5), 403-408.

(13) Bi, Z.; Li, T.; Su, H.; Ni, Y.; Yan, L. Transparent Wood Film Incorporating Carbon Dots as Encapsulating Material for White Light-Emitting Diodes. ACS Sustainable Chem. Eng. 2018, 6 (7), 9314-9323.

(14) Okahisa, Y.; Yoshida, A.; Miyaguchi, S.; Yano, H. Optically Transparent Wood-Cellulose Nanocomposite as a Base Substrate for Flexible Organic Light-Emitting Diode Displays. Compos. Sci. Technol. 2009, 69 (11-12), 1958-1961.

(15) Li, Y.; Cheng, M.; Jungstedt, E.; Xu, B.; Sun, L.; Berglund, L. Optically Transparent Wood Substrate for Perovskite Solar Cells. ACS Sustainable Chem. Eng. 2019, 7 (6), 6061-6067.

(16) Zhu, M.; Li, T.; Davis, C. S.; Yao, Y.; Dai, J.; Wang, Y.; AlQatari, F.; Gilman, J. W.; Hu, L. Transparent and Haze Wood Composites for Highly Efficient Broadband Light Management in Solar Cells. Nano Energy 2016, 26, 332-339.

(17) Gan, W.; Xiao, S.; Gao, L.; Gao, R.; Li, J.; Zhan, X. Luminescent and Transparent Wood Composites Fabricated by Poly(Methyl Methacrylate) and $\gamma$-Fe $2 \mathrm{O}_{3} @_{4}$ YVO ${ }_{4}$ Eu ${ }^{3+}$ Nanoparticle Impregnation. ACS Sustainable Chem. Eng. 2017, 5 (5), 3855-3862.

(18) Liu, Y.; Yang, H.; Ma, C.; Luo, S.; Xu, M.; Wu, Z.; Li, W.; Liu, S. Luminescent Transparent Wood Based on Lignin-Derived Carbon Dots as a Building Material for Dual-Channel, Real-Time, and Visual Detection of Formaldehyde Gas. ACS Appl. Mater. Interfaces 2020, 12 (32), 36628-36638.

(19) Qiu, Z.; Xiao, Z.; Gao, L.; Li, J.; Wang, H.; Wang, Y.; Xie, Y. Transparent Wood Bearing a Shielding Effect to Infrared Heat and Ultraviolet via Incorporation of Modified Antimony-Doped Tin Oxide Nanoparticles. Compos. Sci. Technol. 2019, 172, 43-48.

(20) Yu, Z.; Yao, Y.; Yao, J.; Zhang, L.; Chen, Z.; Gao, Y.; Luo, H. Transparent Wood Containing $\mathrm{Cs}_{\mathrm{x}} \mathrm{WO}_{3}$ Nanoparticles for HeatShielding Window Applications. J. Mater. Chem. A 2017, 5 (13), 6019-6024.

(21) Kortz, C.; Hein, A.; Ciobanu, M.; Walder, L.; Oesterschulze, E. Complementary Hybrid Electrodes for High Contrast Electrochromic Devices with Fast Response. Nat. Commun. 2019, 10 (1), 4874.

(22) Kim, J.; Myoung, J. Flexible and Transparent Electrochromic Displays with Simultaneously Implementable Subpixelated Ion GelBased Viologens by Multiple Patterning. Adv. Funct. Mater. 2019, 29 (13), 1808911.

(23) Jamdegni, M.; Kaur, A. Highly Efficient Dark to Transparent Electrochromic Electrode with Charge Storing Ability Based on Polyaniline and Functionalized Nickel Oxide Composite Linked through a Binding Agent. Electrochim. Acta 2020, 331, 135359.

(24) Rozman, M.; Zener, B.; Matoh, L.; Godec, R. F.; Mourtzikou, A.; Stathatos, E.; Bren, U.; Lukšič, M. Flexible Electrochromic Tape Using Steel Foil with WO3 Thin Film. Electrochim. Acta 2020, 330, 135329.

(25) Mariotti, N.; Bonomo, M.; Fagiolari, L.; Barbero, N.; Gerbaldi, C.; Bella, F.; Barolo, C. Recent Advances in Eco-Friendly and CostEffective Materials towards Sustainable Dye-Sensitized Solar Cells. Green Chem. 2020, 22 (21), 7168-7218.

(26) Syrrokostas, G.; Dokouzis, A.; Yannopoulos, S. N.; Leftheriotis, G. Novel Photoelectrochromic Devices Incorporating Carbon-Based Perovskite Solar Cells. Nano Energy 2020, 77, 105243.
(27) Pulli, E.; Rozzi, E.; Bella, F. Transparent Photovoltaic Technologies: Current Trends towards Upscaling. Energy Convers. Manage. 2020, 219, 112982.

(28) Galliano, S.; Bella, F.; Bonomo, M.; Viscardi, G.; Gerbaldi, C.; Boschloo, G.; Barolo, C. Hydrogel Electrolytes Based on Xanthan Gum: Green Route towards Stable Dye-Sensitized Solar Cells. Nanomaterials 2020, 10 (8), 1585.

(29) Lang, A. W.; Li, Y.; De Keersmaecker, M.; Shen, D. E.; Österholm, A. M.; Berglund, L.; Reynolds, J. R. Transparent Wood Smart Windows: Polymer Electrochromic Devices Based on Poly $(3,4-$ Ethylenedioxythiophene):Poly(Styrene Sulfonate) Electrodes. ChemSusChem 2018, 11 (5), 854-863.

(30) Mi, R.; Li, T.; Dalgo, D.; Chen, C.; Kuang, Y.; He, S.; Zhao, X.; Xie, W.; Gan, W.; Zhu, J.; Srebric, J.; Yang, R.; Hu, L. A Clear, Strong, and Thermally Insulated Transparent Wood for Energy Efficient Windows. Adv. Funct. Mater. 2020, 30 (1), 1907511.

(31) Zhang, L.; Wang, A.; Zhu, T.; Chen, Z.; Wu, Y.; Gao, Y. Transparent Wood Composites Fabricated by Impregnation of Epoxy Resin and W-Doped $\mathrm{VO}_{2}$ Nanoparticles for Application in EnergySaving Windows. ACS Appl. Mater. Interfaces 2020, 12 (31), 3477734783.

(32) Wang, L.; Liu, Y.; Zhan, X.; Luo, D.; Sun, X. Photochromic Transparent Wood for Photo-Switchable Smart Window Applications. J. Mater. Chem. C 2019, 7 (28), 8649-8654.

(33) Montanari, C.; Li, Y.; Chen, H.; Yan, M.; Berglund, L. A. Transparent Wood for Thermal Energy Storage and Reversible Optical Transmittance. ACS Appl. Mater. Interfaces 2019, 11 (22), 20465-20472.

(34) Reinelt, S.; Tabatabai, M.; Moszner, N.; Fischer, U. K.; Utterodt, A.; Ritter, H. Synthesis and Photopolymerization of ThiolModified Triazine-Based Monomers and Oligomers for the Use in Thiol-Ene-Based Dental Composites. Macromol. Chem. Phys. 2014, 215 (14), 1415-1425.

(35) Patel, M. P.; Braden, M.; Davy, K. W. M. Polymerization Shrinkage of Methacrylate Esters. Biomaterials 1987, 8 (1), 53-56.

(36) Li, Y.; Yang, X.; Fu, Q.; Rojas, R.; Yan, M.; Berglund, L. Towards Centimeter Thick Transparent Wood through Interface Manipulation. J. Mater. Chem. A 2018, 6 (3), 1094-1101.

(37) Zandi, M.; Hashemi, S. A.; Aminayi, P.; Hosseinali, F. Microencapsulation of Disperse Dye Particles with Nano Film Coating through Layer by Layer Technique. J. Appl. Polym. Sci. 2011, 119 (1), 586-594.

(38) Fanchiotti, B. G.; Machado, M. P. Z.; de Paula, L. C.; Durmuş, M.; Nyokong, T.; da Silva Gonçalves, A.; da Silva, A. R. The Photobleaching of the Free and Encapsulated Metallic Phthalocyanine and Its Effect on the Photooxidation of Simple Molecules. J. Photochem. Photobiol., B 2016, 165, 10-23.

(39) Li, Y.; Fu, Q.; Rojas, R.; Yan, M.; Lawoko, M.; Berglund, L. Lignin-Retaining Transparent Wood. ChemSusChem 2017, 10 (17), 3445-3451.

(40) Pike, L. Optical Properties of Packaging Materials. J. Plast. Film Sheeting 1993, 9 (3), 173-180.

(41) Chen, H.; Baitenov, A.; Li, Y.; Vasileva, E.; Popov, S.; Sychugov, I.; Yan, M.; Berglund, L. Thickness Dependence of Optical Transmittance of Transparent Wood: Chemical Modification Effects. ACS Appl. Mater. Interfaces 2019, 11 (38), 35451-35457.

(42) Li, Y.; Fu, Q.; Yang, X.; Berglund, L. Transparent Wood for Functional and Structural Applications. Philos. Trans. R. Soc., A 2018, 376 (2112), 20170182.

(43) Höglund, M.; Johansson, M.; Sychugov, I.; Berglund, L. A. Transparent Wood Biocomposites by Fast UV-Curing for Reduced Light-Scattering through Wood/Thiol-Ene Interface Design. ACS Appl. Mater. Interfaces 2020, 12 (41), 46914-46922.

(44) Li, Y.; Gu, X.; Gao, H.; Li, J. Photoresponsive Wood Composite for Photoluminescence and Ultraviolet Absorption. Construction and Building Materials 2020, 261, 119984. 


\section{Supporting information}

\section{Reversible dual-stimuli responsive chromic}

\section{transparent wood bio-composites for smart window}

\section{applications}

Archana Samanta*a ${ }^{a}$, Hui Chen ${ }^{b}$, Pratick Samanta ${ }^{b}$, Sergei Popov ${ }^{a}$, Ilya Sychugov ${ }^{a}$, and Lars A. Berglund ${ }^{b}$

${ }^{\text {a }}$ Department of Applied Physics, KTH Royal Institute of Technology, Stockholm 114 19, Sweden

${ }^{\mathrm{b}}$ Department of Fibre and Polymer Technology, Wallenberg Wood Science Center, KTH Royal Institute of Technology, Stockholm 100 44, Sweden

*E-mail: archanas@kth.se 

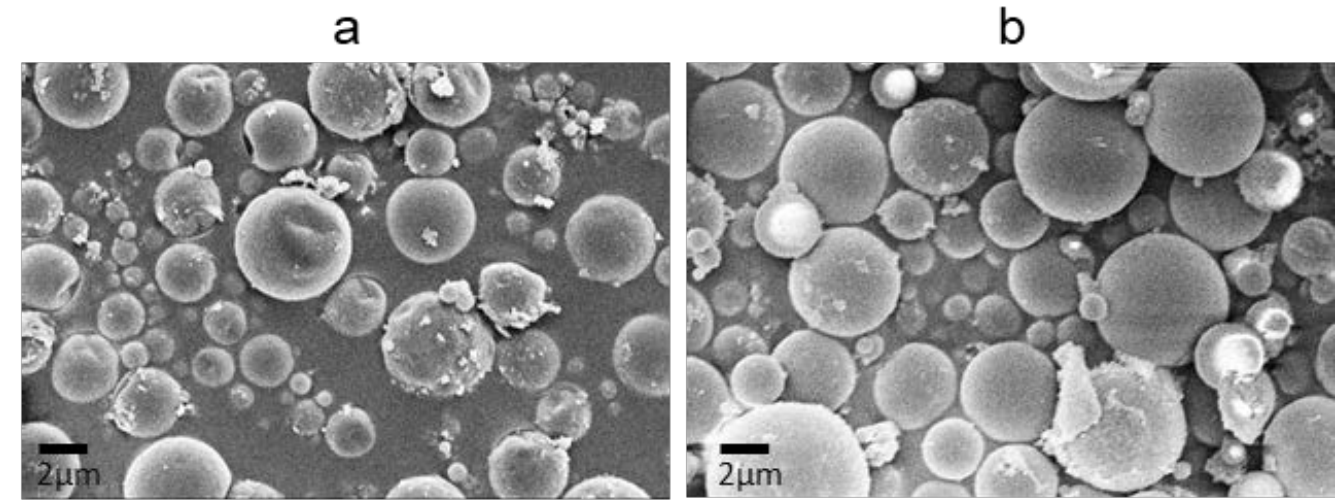

Figure S1. SEM images of (a) TC and (B) PC pigments. 

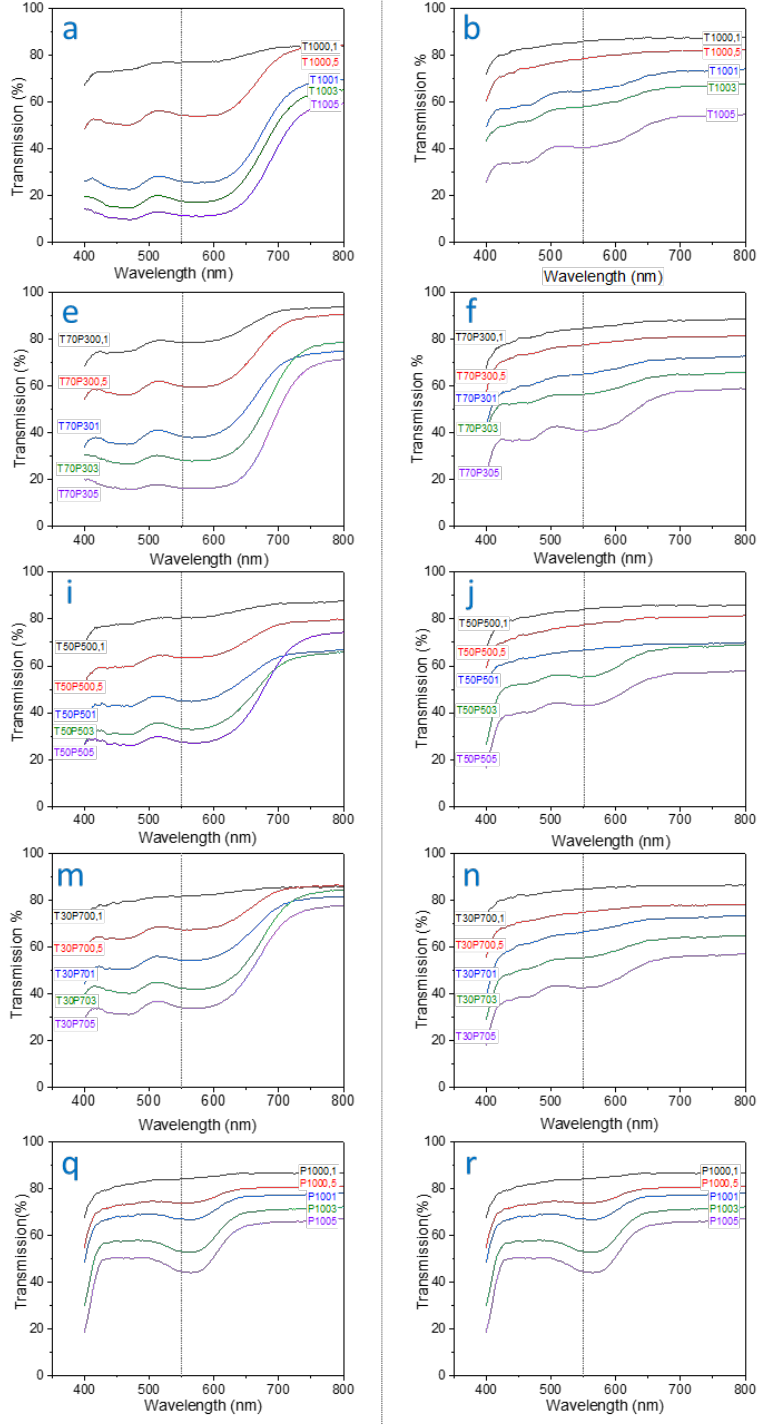

$$
\mathrm{T}\left(20 \pm 1^{\circ} \mathrm{C}\right)<\mathrm{PCT}
$$
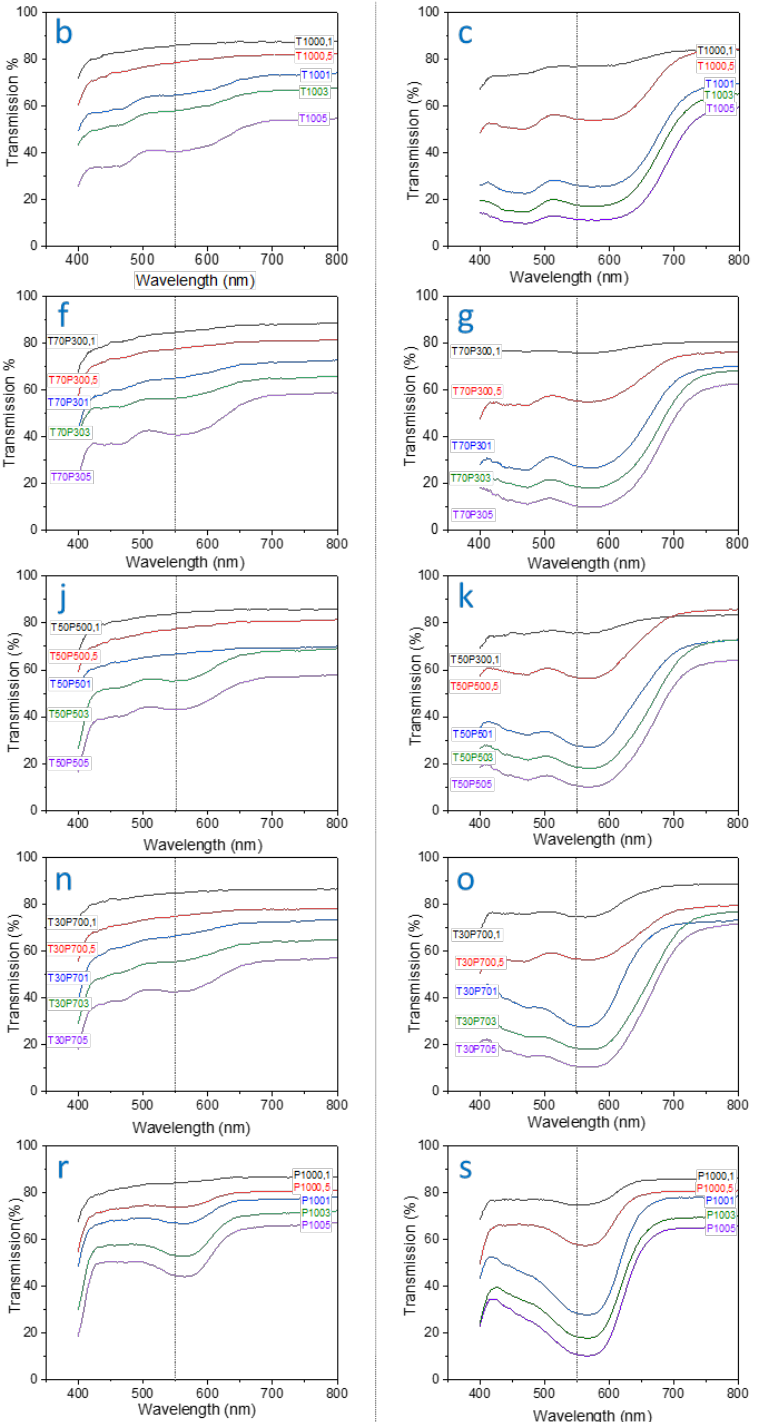

$\mathrm{T}\left(35 \pm 2^{\circ} \mathrm{C}\right)>\mathrm{PCT}$
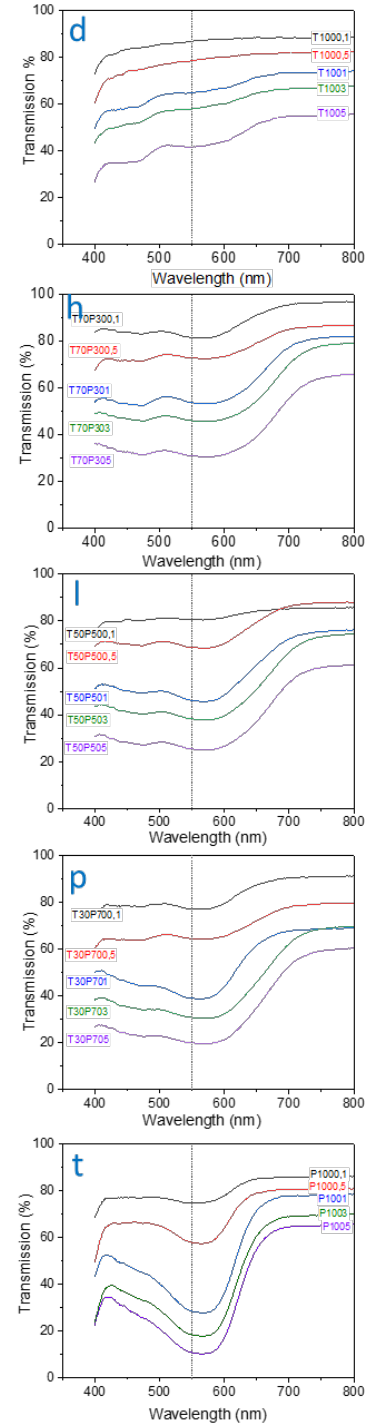

$\mathrm{T}\left(35 \pm 2^{\circ} \mathrm{C}\right)>\mathrm{PCT}$ UV $(360 \mathrm{~nm})$

Figure S2. Transmission properties of chromic TW composites containing various compositions of chromic contents on exposure to temperature and UV. The gray line corresponds to transmittance values at $550 \mathrm{~nm}$. 
Table S1. Transmission values of chromic TW at $550 \mathrm{~nm}$ on exposure to UV, temperature or both.

\begin{tabular}{|c|c|c|c|c|c|}
\hline \multirow{2}{*}{$\begin{array}{c}\text { Sample } \\
\text { code }\end{array}$} & \multicolumn{4}{|c|}{ Transmission at $550 \mathrm{~nm}(\%)$} & \multirow{2}{*}{$\begin{array}{c}\text { Haze at } 550 \\
\text { nm (\%) }\end{array}$} \\
\hline & $\mathrm{T}<\mathrm{PCT}$ & $\mathrm{T}>\mathrm{PCT}$ & $\begin{array}{c}\text { UV, } \\
\mathrm{T}<\mathrm{PCT}\end{array}$ & $\begin{array}{c}\text { UV, } \\
\text { T > PCT }\end{array}$ & \\
\hline $\begin{array}{c}\text { Thiol-ene } \\
\text { TW }\end{array}$ & $87 \pm 2$ & $87 \pm 2$ & $87 \pm 2$ & $87 \pm 2$ & $47 \pm 2$ \\
\hline $\mathrm{T} 1000.1$ & $76 \pm 2$ & $86 \pm 1$ & $76 \pm 2$ & $86 \pm 1$ & $57 \pm 1$ \\
\hline $\mathrm{T} 1000.5$ & $54 \pm 1$ & $79 \pm 2$ & $54 \pm 1$ & $79 \pm 2$ & $61 \pm 1$ \\
\hline T1001 & $26 \pm 1$ & $64 \pm 2$ & $26 \pm 1$ & $64 \pm 1$ & $68 \pm 2$ \\
\hline T1003 & $18 \pm 1$ & $58 \pm 2$ & $18 \pm 1$ & $58 \pm 2$ & $73 \pm 2$ \\
\hline T1005 & $10 \pm 2$ & $40 \pm 3$ & $10 \pm 2$ & $40 \pm 3$ & $78 \pm 2$ \\
\hline T30Р700.1 & $82 \pm 2$ & $84 \pm 3$ & $75 \pm 2$ & $77 \pm 2$ & $53 \pm 2$ \\
\hline T30P700.5 & $67 \pm 3$ & $75 \pm 2$ & $57 \pm 2$ & $64 \pm 3$ & $58 \pm 1$ \\
\hline Т30Р701 & $54 \pm 2$ & $65 \pm 2$ & $26 \pm 3$ & $39 \pm 2$ & $60 \pm 1$ \\
\hline Т30Р703 & $43 \pm 2$ & $54 \pm 2$ & $18 \pm 2$ & $30 \pm 3$ & $65 \pm 2$ \\
\hline T30Р705 & $34 \pm 2$ & $43 \pm 2$ & $10 \pm 1$ & $19 \pm 2$ & $70 \pm 2$ \\
\hline T50P500.1 & $80 \pm 3$ & $85 \pm 2$ & $75 \pm 2$ & $79 \pm 3$ & $55 \pm 2$ \\
\hline T50P500.5 & $64 \pm 2$ & $76 \pm 2$ & $56 \pm 2$ & $69 \pm 3$ & $60 \pm 1$ \\
\hline T50P501 & $46 \pm 1$ & $68 \pm 3$ & $27 \pm 2$ & $44 \pm 3$ & $63 \pm 2$ \\
\hline T50P503 & $36 \pm 3$ & $56 \pm 3$ & $18 \pm 3$ & $38 \pm 2$ & $68 \pm 2$ \\
\hline T50P505 & $28 \pm 3$ & $42 \pm 2$ & $10 \pm 2$ & $25 \pm 2$ & $72 \pm 2$ \\
\hline T70Р300.1 & $78 \pm 3$ & $85 \pm 2$ & $75 \pm 2$ & $82 \pm 2$ & $56 \pm 1$ \\
\hline T70Р300.5 & $60 \pm 2$ & $77 \pm 4$ & $55 \pm 2$ & $71 \pm 4$ & $60 \pm 2$ \\
\hline T70Р301 & $38 \pm 3$ & $65 \pm 2$ & $27 \pm 3$ & $53 \pm 3$ & $67 \pm 2$ \\
\hline Т70Р303 & $29 \pm 2$ & $57 \pm 3$ & $18 \pm 2$ & $46 \pm 2$ & $71 \pm 2$ \\
\hline T70P305 & $21 \pm 2$ & $41 \pm 2$ & $11 \pm 2$ & $31 \pm 2$ & $76 \pm 2$ \\
\hline P1000.1 & $84 \pm 2$ & $84 \pm 2$ & $74 \pm 2$ & $74 \pm 2$ & $54 \pm 1$ \\
\hline P1000.5 & $73 \pm 3$ & $73 \pm 3$ & $58 \pm 3$ & $58 \pm 3$ & $59 \pm 1$ \\
\hline P1001 & $66 \pm 4$ & $66 \pm 4$ & $28 \pm 3$ & $28 \pm 3$ & $61 \pm 2$ \\
\hline P1003 & $53 \pm 1$ & $53 \pm 2$ & $18 \pm 2$ & $18 \pm 2$ & $65 \pm 2$ \\
\hline P1005 & $44 \pm 2$ & $44 \pm 2$ & $10 \pm 3$ & $10 \pm 3$ & $71 \pm 2$ \\
\hline
\end{tabular}



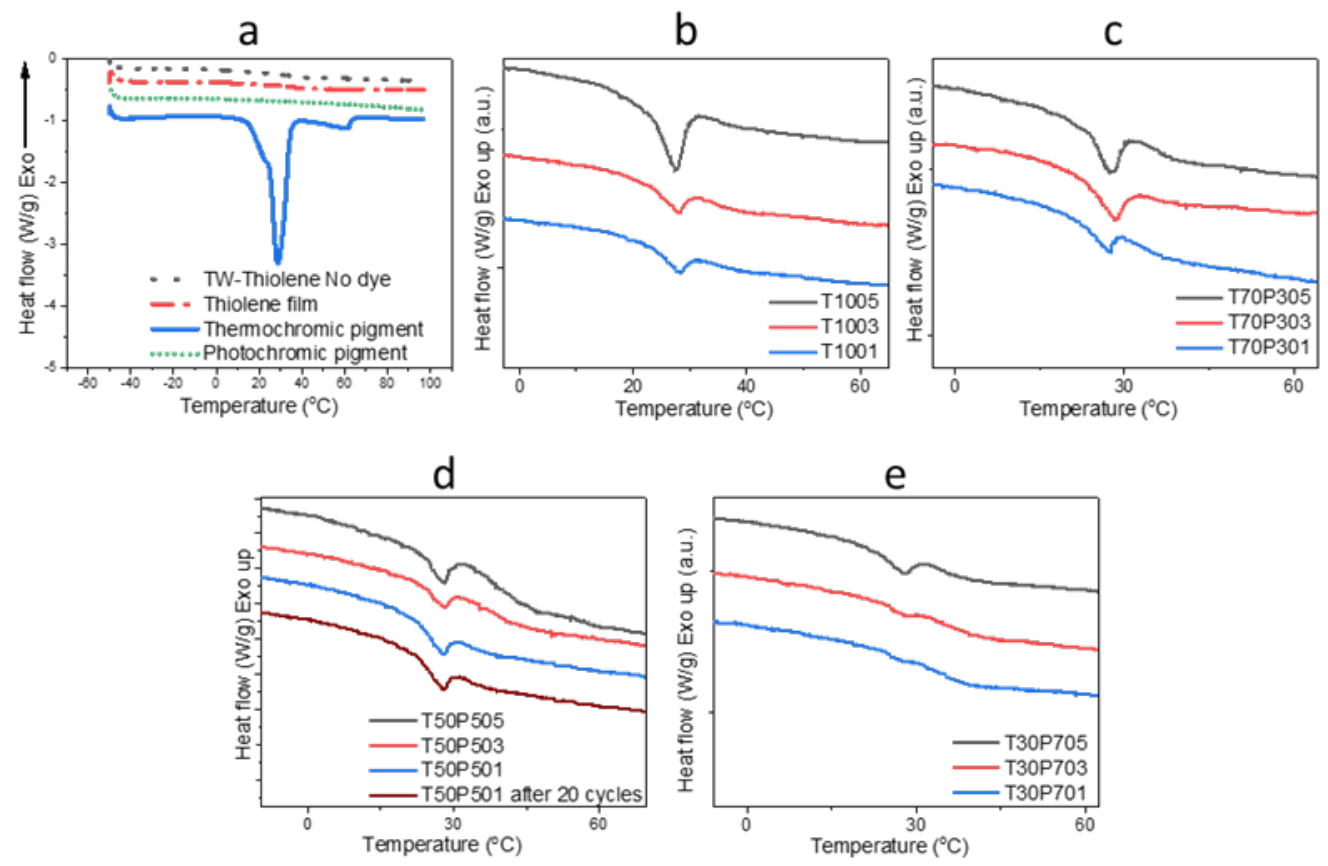

Figure S3. Thermal analysis of TW composites. Heating cycle of (a) native chromic components and thiol-ene film, (b) T1001, T1003, T1005, (c) T70P301, T70P303, T70P305, (d) T50P501, T50P503, T50P505, (e) T30P701, T30P703, T30P705.
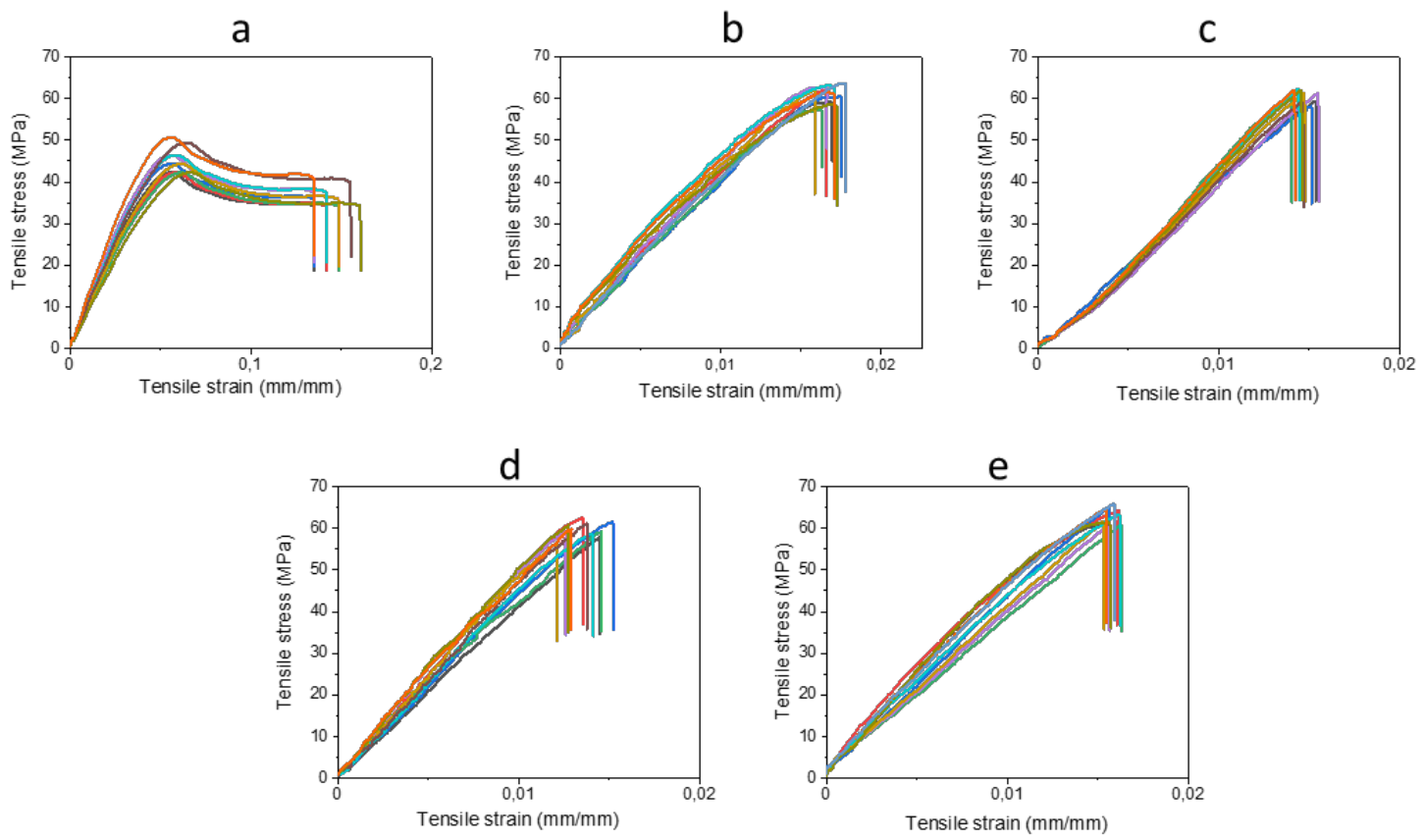

Figure S4. Mechanical property analysis of TW composites. (a) Thiol-ene film, (b) Thiol-ene TW (no chromic component), (c) T50P501, (d) P1001, (e) T1001. 